\title{
ELECTROENCEPHALOGRAPHIC STUDIES ON FATIGUE INDUCED BY ENFORCED SWIMMING IN THE WHITE RAT
}

\author{
NAOSABURO YOSHIL, KAZUO TSUKIYAMA \\ AND KIYOSHI HORIUCHI* \\ Second Department of Physiology, Osaka University Medical School
}

Grüttner and Bankálò (1), Motokawa, Mita and Tsujiguchi (2) reported electroencephalographic studies on mental fatigue, but did not study brain fatigue after somatic work. Changes in reflex function after several types of athletic sports $(3,4)$ and brain fatigue after somatic and mental work $(5,6,7,8)$ were examined in our laboratory. In this paper, the electroencephalographic changes were studied in fatigued rats by enforced swimming with a view to find the cerebral function in somatically fatigued state.

\section{METHODS}

Thirteen adult rats (100-200 g. in body weight) were forced to swim in a vessel which was filled to seven-tenths of its capacity with water $\left(23-30^{\circ}\right.$ C.), until the rats were fatigued enough to the point of drowning. EEG's were lead off bipolarly from the two electrodes previously inserted under the skull and fixed on the parietal and occipital cortices respectively, and recorded by a four stage resistance-capacity coupled amplifier ( $0.2 \mathrm{sec}$. time constant) and an electromagnetic oscillograph. Each experiment was carried out several days after the operation of insertion of the electrodes (9).

\section{RESULTS}

Normal EEG of white rat consists of regular 7-10 (6-12) per second waves (basic waves) and superimposed less regular 16-20 or more per sec. waves (small fast waves), as has been reported previously (9).

EEG-changes resulting from enforced swimming were characterized by suppression of the basic waves and increase in the small fast waves (that is, increase in average frequency per sec. and decrease in average amplitude), but significantly abnormal waves were not observed even when the rat was exhausted. The EEG-changes could be classified as follows:

Type 1: As the rat became fatigued, basic waves were suppressed and became less regular, while the small fast waves increased in number. No further significant changes were seen in the EEG even when the rat was extremely fatigued to the point of drowning. When the swimming was ceased and the rat

Received for publication June 23, 1952.

* 吉井值三郎, 築山一夫, 堀内 泠 
placed on the table, the EEG recovered gradually. This type was most common and was observed in all rats except two (fig. 1).

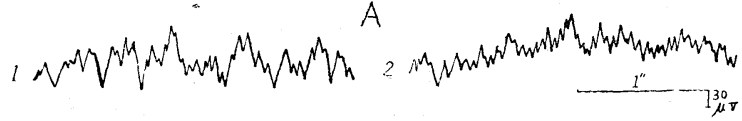

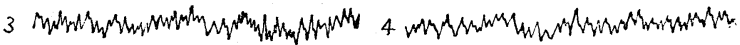
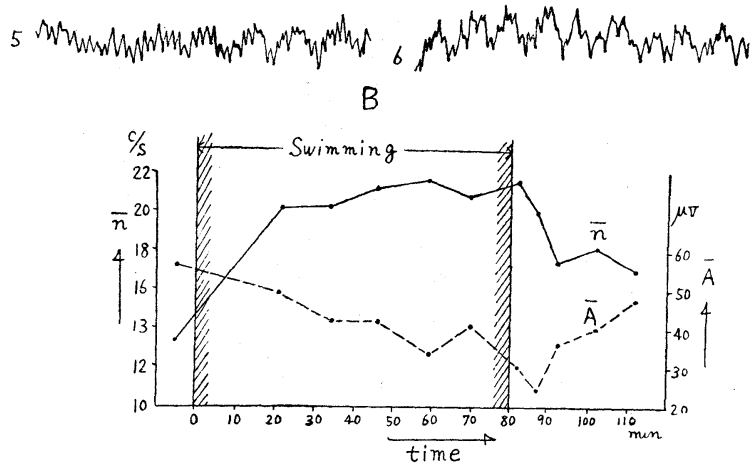

FIG. 1. EEG-changes in fatigued state (Type 1).

$A$ : EEG's in fatigued state following enforced swimming.

1: before swimming.

2: soon after swimming for 20 minutes.

3: soon after swimming for 50 minutes.

4: soon after swimming for 70 minutes.

5: 10 minutes after the end of swimming for 80 minutes.

6: 30 minutes later.

$B$ : Average frequency per sec. $(\bar{n})$ and average amplitude $(\bar{A})$ of the EEG's in fatigued state.

Type 2: As in type 1, the basic waves were suppressed and the small fast waves increased in number in the initial stage, but both frequency and amplitude of the fast waves increased thereafter as fatigue became severe. This type was seen only in one rat (fig. 2).

FIG. 2. EEG-changes in fatigued state (Type 2).

$A$ : EEG's in fatigued state following enforced swimming.

1: before swimming.

2 : soon after swimming for 8 minutes.

3: soon after swimming for 30 minutes.

4: 5 minutes after the end of swimming for 40 minutes.

5 : 30 minutes later.

6: 60 minutes later.

$B$ : Average frequency per sec. $(\bar{n})$ and average amplitude $(\bar{A})$ of the EEG's in fatigued state.

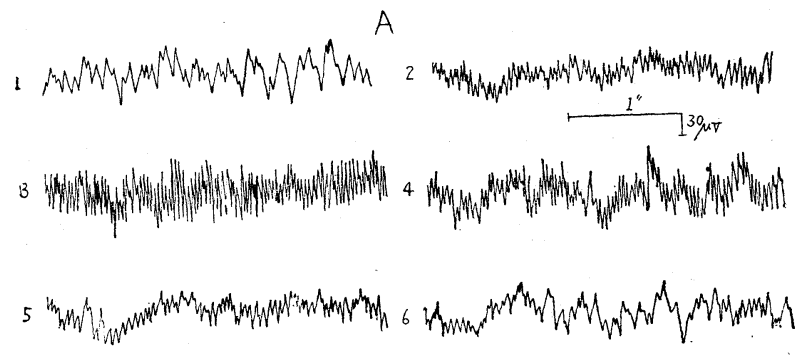

B

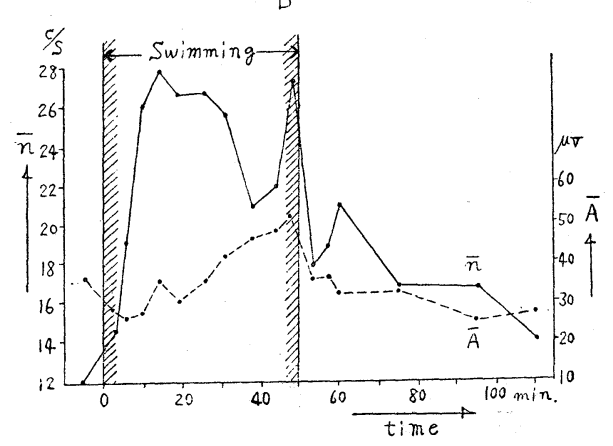


Type 3: Suppression of the basic waves and increase of the small fast waves were noticed as in type 1, but 6-7 per sec. slow waves appeared in the recovery stage. This type was seen also in only one rat (fig. 3 ).

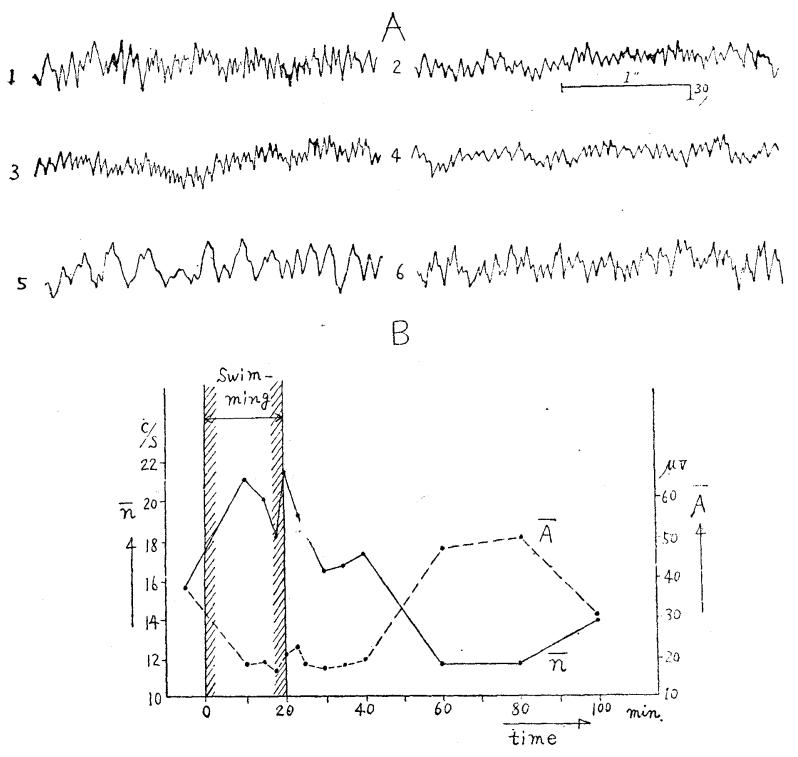

FIG. 3 : EEG-changes in fatigued state (Type 3.).

$A$ : EEG's in fatigued state following enforced swimming.

1: before swimming.

2: soon after swimming for 10 minutes.

3: soon after swimming for 20 minutes.

4: 20 minutes after the end of swimming for 20 minutes.

5: 60 minutes later.

6: 90 minutes later.

$B$ : Average frequency per sec. $(\bar{n})$ and average amplitude $(\bar{A})$ of the EEG's in fatigued state.

\section{CONSIDERATIONS}

The EEG's of rats in fatigued state induced by forced swimming, were characterized by the suppression of the basic waves and increase in the small fast waves (i.e. increase in average frequency per sec. and decrease in average amplitude). But an increase in both frequency and amplitude was noticed in one case (Type 2), and increase in amplitude associated with decrease in frequency (i.e. appearance of slow waves) was seen in the recovery stage of another case (Type 3 ).

The suppression of the basic waves and increase in the small fast waves indicate an excited state while augmentation of the basic and slow waves indicates an inhibited state of the cerebrum, according to our hypothesis concerning the electroencephalographic level of the cerebral excitatory state (10). Therefore, the EEG-changes in the fatigued state after swimming indicate an enhanced level in cerebral excitation, in general. The increase in the amplitude of the fast waves in type 2 indicates a higher excitatory level than type 1, while the appearance of the slow waves in type 3 indicates a drowsy state after severe fatigue and a lowered level of the cerebral excitatory state.

It was found, in studies on fatigue in man examined by the "time-estimation method" of Yoshii (5), that an excited period (the initial period of fatigue) was followed by an inhibited period (fatigued state in the usual sense). We found, furthermore, the existence of exited and inhibited periods in the fatigue of white rats in experiments on repeated behaviors of conditioned jumping (7). We 
know also, by electroencephalographic studies on the "time-estimation method" in man (6) and conditioned behaviors in rats (8), that the excited period is characterized by suppression of the basic waves and increase of the small fast waves, the inhibited period by augmentation of the basic waves or appearance of slow waves. These observations were mostly concerned with mental fatigue. In this paper purely somatic fatigue' was studied and only the excited state was found, even when the animal was thought to be exhausted, except in one case in which the slow waves appeared in the recovery process.

These results and considerations suggest that purely somatic fatigue does not lead to an inhibited state of the brain but maintains an excited or awakened state of the brain even when somatic fatigue was considered extremely severe. This is the difference in somatic fatigue from mental fatigue which easily induces an inhibited or drowsy state of the brain.

\section{SUMMARY}

1. Changes in the cerebral functional state were studied electroencephalographically in fatigue induced by forced swimming of 13 rats.

2. The characteristic changes of the EEG's in fatigued rats were the suppression of the basic waves and increase of the small fast waves, which indicate an enhanced state of cerebral excitatory level and considered to be an excited period of fatigue (Type 1).

3. Both the average frequency and amplitude increased in one rat in the fatigued state, and indicate a higher excitatory level than type 1 (Type 2).

4. Slow waves appeared in the recovery stage in one rat, and indicated a drowsy state or lowered level in cerebral excitation and is considered to be an inhibited state of fatigue (Type 3).

5. It has already been shown by us that the excited period was generally followed by an inhibited period in mental fatigue, but only an excited state of the brain was found in somatic fatigue, even though the animal was thought to be extremely fatigued, except for one case in the recovery stage.

\section{REFERENCES}

1. GRÜTtNeR, R. UND A. BANKÁLÒ. Über Ermüdung und Schlaf auf Grund hirnbioelektrischer Untersuchungen. Arch. Psychiat. Nevvenkr. 111: 625, 1940.

2. Motokawa, K., S. Mita AND K. TSujiguchi. EEG and mental fatigue. J. Physiol. Soc. Jap. 9: 690, 1944 (in Japanese).

3. Kawamura, Y., S. Hiwatari, K. Tsukiyama, K. Hiraiwa, K. Tamai, Y. KawaNISHI, K. UCHIHORI, M. NAKAJI AND A. NAKAI. The medical examination of participants of athletics, Report No. 1. Med. J. Osaka Univ. Japanese Edition, 2: 233, 1950 (in Japanese).

4. KaW AmURA, Y., Y. OGa, S. Hiw ATARI, K. TSukiYama, K. HiraiWA, T. Horiguchi, S. HATTORI, H. HASHIMOTO AND N. NAGASAKI. The medical examination of participants of athletics, Report No. 2. Med. J. Osaka Univ. Japanese Edition, 3: 203, 1951 (in Japanese).

5. Yoshir, N. Studies on fatigue examined by "time-estimaticn method" (I). J. Physiol. Soc. Jap. 9: 793, 1944 (in Japanese).

6. YOShII, N., K. TSUKIYAMA AND K. HORIUCHI. Electroencephalographic studies on the 
"time-estimation method" as a fatigue test. (unpublished).

7. YoshiI, N. AND K. TSUKIYAMA. Some factors relating to the central excitatory level in conditioned jumping behavior. Med. J. Osaka Univ. 2: 133, 1950.

8. YOShII, N. AND K. TSUKIYAMA. Electroencephalographic studies on conditioned behavior of white rat. Jap. J. Physiol. 2: 186, 1952.

9. Yoshil, N. AND K. TsukiyamA. Normal EEG and its development in the white rat. Jap. J. Physiol. 2 : 34, 1951.

10. YOShII, N. AND K. TSUKIYAMA. On the abnormal EEG of white rat. The relationship between the cerebral excitatory level and the EEG. Med. J. Osaka Univ. 3: 129, 1952. 